\title{
Understanding Conceptual Impact of Scientific Knowledge on Policy: The Role of Policymaking Conditions
}

\author{
Jakob Edler ${ }^{1,2}\left(\right.$ Maria Karaulova $^{1}\left(\mathbb{D} \cdot{\text { Katharine } \text { Barker }^{2}}^{2}\right.$
}

Accepted: 10 January 2022 / Published online: 12 February 2022

(C) The Author(s) 2022

\begin{abstract}
This paper presents a framework to understand the impact of scientific knowledge on the policy-making process, focusing on the conceptual impact. We note the continuing dissatisfaction with the quality and effects of science-policy interactions in both theory and practice. We critique the current literature's emphasis on the efforts of scientists to generate policy impact, because it neglects the role of 'user' policymaking organisations. The framework offered in the paper develops an argument about the essential role of institutional conditions of policy 'users' for scientific knowledge to achieve impact. The framework is informed by the reflexive institutionalist and the neo-institutionalist theoretical approaches. Its main contribution is in outlining the intra- and inter-organisational conditions of policymaking organisations, along with personal characteristics of individual policy officials that influence the likelihood of scientific knowledge to generate conceptual impact. We also offer an operationalisation of the framework. The wider relevance of the paper is in moving the focus from the activities of scientists and the incentive structure in scientific organisations to the policy user side.
\end{abstract}

Keywords Science policy $\cdot$ Discursive institutionalism $\cdot$ Research-informed policy $\cdot$ Research impact

Jakob Edler

jakob.edler@isi.fraunhofer.de

1 Fraunhofer Institute for Systems and Innovation Research, Breslauer Str. 48, 76139 Karlsruhe, Germany

2 Manchester Institute of Innovation Research, Alliance Manchester Business School, University of Manchester, Booth St West, Manchester M15 6PB, UK 


\section{Introduction}

How can science have an impact on policymaking? This question has been with us since the institutionalised public funding of research began and has sparked a wideranging discussion with a variety of perspectives and approaches to conceptualise and measure the impact of science (Caplan 1979; Weiss 1979; Borgenschneider and Corbett 2010; Bozeman and Sarewitz 2011; Matt et al. 2017). We contribute to this debate by developing a concept that focuses on conditions on the side of scientific knowledge users. This was motivated by the four observations described below regarding the impact of science ${ }^{1}$ on policymaking.

First, despite a long history of looking at science - policy relationships and the use of scientific expertise and evidence in policymaking, there is still dissatisfaction with how and the extent to which science actually informs policy, especially scientific research from academia (Almeida and Báscolo 2006; Kenny et al. 2017). Second, science, technology and innovation policies are increasingly being formulated to address global challenges and societal missions (Weber and Rohracher 2012; Mazzucato 2018; European Commission 2018). Since the Second World War, science has always included an element of mission orientation. The last decade, at least in Europe, has seen a broadening of this approach in science funding, often framed in the language of crisis, response urgency and severity of the challenges (Boon and Edler 2018; Kuhlmann and Rip 2018). As one consequence, science's impact on policy and on society has come to the fore again as a major justification of scientific activity.

Third, there is an increasing demand for scientists to produce impactful knowledge (Kessler and Glasgow 2011; Brownson et al. 2006). Many research councils, such as the UK Research and Innovation Council, the US National Science Foundation, and the European Framework Programmes, now explicitly ask for engagement strategies in funding applications. In performance-based funding systems, such as the UK Research Excellence Framework, the explicit demonstration of impact is becoming increasingly important for the assessment of organisations (Hicks 2012), and the scientists working within them (Wilkinson 2017). This places the onus of generating impact on scientists: to choose the right topics, develop engagement strategies, and trace the impact their research has on society. Fourth, a persisting idea in policymaking is that objective evidence can be produced based on rigorous approaches, translated into layman language, and then used by policy actors to codetermine decisions (Parsons 2002; Sanderson 2009; Mthiyane and Breckon 2020). The more convincing the evidence and its translation, the more likely it will influence the policymaking process. The 'quality' of the evidence and the associated expert advice determine the impact.

We believe a change of perspective is needed to balance our understanding of how science can generate policy impact. If science's impact on policymaking is considered insufficient, and at the same time, more scientific support is needed to

\footnotetext{
${ }^{1}$ In the European tradition, the term scientists includes social scientists as well unless otherwise indicated.
} 
tackle urgent challenges, we suggest a complementary perspective of the sciencepolicy relationship. We develop a novel conceptual framework to shift the perspective towards the users of science in the policymaking arena. This framework suggests that how 'user' organisations search for and absorb scientific knowledge co-determines its impact as much as the circumstances in which it was produced, and the engagement efforts of scientists. In particular, the framework conceptualises the conditions that influence the ability and willingness of policymakers to access and use scientific research. We focus on the conditions that influence the likelihood of scientific knowledge to create conceptual impact. This occurs if a change can be observed in policymakers' thinking about the nature of policy problems, their underlying causalities, and possible solutions (Amara et al. 2004). Despite many excellent political science and STS contributions on the role of science in achieving policy change (Sabatier 1988; Smith 2013a; Jäger and Ferguson 1993), conceptual impact remains an overlooked element of this literature, because it is not always evident in final policy outcomes.

Scientific knowledge, encompassing scientific evidence and ideas, is our primary subject of interest. Science is a specific knowledge production enterprise associated with particular goals and norms (Merton 1973). The term 'scientific evidence' differs from 'research evidence', which is a related, but broader concept. The term 'evidence' is broader still and signifies any facts or information used to make decisions (Nutley et al. 2007). In the next sections, we will also use the terms 'research evidence' and 'research impact' only when discussing the literature that used a broader scope and did not distinguish science specifically. However, in developing the framework, we focused primarily on the conditions shaping scientific knowledge uptake within the specific relationship between the domains of policy and science.

We grounded the framework on political science approaches that focus on sensemaking and interpreting as a major dimension of the policymaking process and employed reflexive (Edler 2003) or discursive (Schmidt 2008, 2010, 2012, 2002) institutionalism. This conceptualises policy change as primarily ideational, the result of actors deliberating about, and reflecting on issue framing, policy problems and policy options. This approach does not neglect power, politics, or polity. However, its epistemological and ontological stance enables us to focus on knowledge-driven cognitive and normative dynamics. We also stress that policymaking takes place in organisations. To understand how organisational context influences scientific knowledge uptake, we draw on Scott (2014) to operationalise the conditions affecting the ideational process. We acknowledge that the meaning of (scientific) ideas and knowledge changes during the different - stylised - stages of the policy process (Howlett 2009).

Although applying the framework on its own will not fully explain the mechanisms and limitations of using scientific knowledge in the policymaking process, it contributes to the literature by complementing, rather than replacing, existing approaches. Its shift in focus enables us to better understand and systematically address (i) the role of the user side and (ii) the often overlooked conceptual impact of research.

The paper is structured as follows. In Section 2, we review the literature on the impact of research on policy in order to substantiate the lack of attention to the user 
side and conceptual impact. Section 3 defines the notion of conceptual impact. Section 4 reviews reflexive (discursive) institutional theory and lays the foundation for the framework. Section 5 describes the framework and its components. Section 6 discusses the merits of the framework and concludes the paper.

\section{A Supply Bias of Impact Studies}

As the increasingly widespread use of accountability tools in science governance places the onus of creating, tracking and reporting impacts on researchers, there is a need to refocus on the users of research in policymaking. Various approaches to evaluating research and their effects on science and scientists are widely debated (Donovan 2011; Penfield et al. 2013; Thomas et al. 2020; de Rijcke et al. 2016; Watermeyer 2016). Typically, instruments cover both scientific excellence and societal impact (Bornmann 2013; Martin 2011). In many countries, one consequence of performance-based research evaluation has been the requirement for the scientists to demonstrate their research impacts to justify continued funding. Following this rationale, multiple analytical frameworks have suggested practical ways of monitoring, assessing and reporting the impact of research. We review key milestones in this literature, in order to highlight the role of research users and the value of this additional perspective.

Early approaches used classical input-output-outcome-impact models, and attributed impacts to funded research by identifying the activity, a concrete project or even a programme that led to the impact and the scale of the impact. Currently, theory-based evaluation approaches have largely replaced such linear view. The most influential models include the payback framework of Donovan and Hannay (2011) for health research, and the public value framework of Bozeman and Sarewitz (2011). They share a common weakness in that they aim to identify concrete and short-term impacts and outcomes. Critics noted that the impact of science is a longterm process that may not always be clearly identifiable and attributable to particular projects. Some impacts from certain types of research are easier to capture, while others are hardly identifiable or much harder to trace (Muhonen et al. 2020).

Separately, the scholarship contributed to an understanding of how scientists can achieve better societal impacts. Improving the delivery of information and ensuring the salience (timeliness), credibility (weight of scientific claims) and legitimacy (the proper process of bringing the information into the policy domain) of scientific knowledge prove to be among the most important factors (Cash et al. 2003; Nutley et al. 2007). Authors also offer strategies to improve impact, e.g. facilitating useful interactions, co-creation, adopting proper knowledge translation strategies, etc. (Broström and McKelvey 2017; Weichselgartner and Kasperson 2010; Armstrong et al. 2013; van der Arend 2014). Typically, research on the impact of science offers ways for scientists to improve the format and delivery of their research and only laterally concerns the demand side (Sarewitz and Pielke 2007). It also downplays policy outcomes that are not attributable to concrete scientific projects and therefore not usable in research impact assessment. 
The SIAMPI (Spaapen and van Drooge 2011) and ASIRPA (Joly et al. 2015) approaches are two significant developments that have attempted to address these shortcomings. Both emphasise the importance of interaction between science and society, challenge the simple linear models of research impact and reject attribution in favour of understanding the contribution of research to a broader societal effect. Both stress the non-linear, multi-stakeholder and often long-term processes of impact and seek to portray the pathways to impact using case studies. In SIAMPI, the notion of "productive interactions" (Spaapen and van Drooge 2011; De Jong et al. 2014) refers to direct and indirect interactions of scientists with non-scientist audiences, and labels them "productive" if either side changes their actions. The early interactions between researchers and "users" can point to where policy impact may occur regardless of whether it actually does. ASIRPA produced a replicable case study-based method to trace the long-term contribution of research of a government laboratory. More theoretically grounded than SIAMPI, it examined the roles of intermediaries and networks in societal impact, which was, unsurprisingly, frequently mediated through policy change.

The common gap in the frameworks reviewed so far is that they are not concerned with understanding the organisational conditions for impact on the user side. Instead, they look at the individual actors, interactions, and pathways. However, organisational conditions could play a very significant role in policy. Policy development is a complex process that is driven by values and interests as much as by evidence and research (Hall 1993). Policymakers operate within the constraints of policy development cycles (Kingdon 1984), but are also influenced by the dominant discourse in their organisational environment and their own preconceptions of valuable knowledge (Amara et al. 2004). Organisational environments influence the sense-making of individual policymakers. Health research, for example, has a strong evidence-based practice mandate (Hanney and GonzálezBlock 2009), while a scientific basis is much less common in other policy areas. The ability of scientists to influence policy development is moderated by these various factors.

Research utilisation is one strand that has explicitly considered the organisational dimension. These studies, predominantly of policy and healthcare, use specialised survey tools to examine research use practices in public settings. They have identified three groups of factors that influence research use by public officials: organisational factors, individual preferences, and barriers. Organisational factors, such as the availability of knowledge brokers, sufficient resources, and a favourable organisational culture, are positively associated with research use (Lomas 2007; Crona and Parker 2011; Belkhodja 2014). Individual traits, such as background and social capital, are equally important; for example, public officials with advanced degrees or work experience in academia are more likely to use research (Jennings and Hall 2012; Ouimet et al. 2010). Public officials vary in their openness to research from different sources and use different types of research in different ways, e.g. instrumentally, symbolically, and conceptually (Amara et al. 2004; Jbilou et al. 2007). Finally, certain barriers obstruct research use: ideological differences, differences in risk perception, lack of contact to and different time frames for knowledge demand and supply (Almeida and Bascolo 2006). 
Research use evidence in the utilisation literature provides a solid foundation to analyse the conditions for research impact. We suggest that the factors influencing the impact process are related to the factors that influence research use. Analysing policy organisations' institutional and organisational conditions in detail can conceptualise the missing link in our understanding of how scientific knowledge can achieve lasting impact on policy.

\section{Conceptual Impact}

Having established why we focus on the organisational conditions on the user side, we now explain our focus on conceptual impact. The impact of science is typically defined as a change in the thinking or behaviour of societal actors (Hessels and Lente 2010; Spaapen and van Drooge 2011). The established typologies usually categorise impacts into those affecting cognition (conceptual), those that aid decision-making (instrumental) and those selected to support pre-existing opinions (symbolic) (Amara et al. 2004; Estabrooks 1999; Landry et al. 2003; Thompson et al. 2007; Weiss 1979). Conceptual impact has been a victim of assessment frameworks that overemphasise the traceable, attributable outcomes of research. Studies have focused mainly on instrumental impact, because only a change in action can be reliably monitored and assessed (Thompson et al. 2007). Identifying and assessing a change in thinking is much harder than spotting changes in behaviour and decision-making. In order to discern conceptual impact, studies need to question actors directly. However, even the actors themselves are not always able to pinpoint how they are using research (Kanneman and Tversky 2000 in Contandriopoulos et al. 2010).

Further, in policy settings, changes in a person's thinking (e.g. conceptual impact) do not always manifest in changes in political action, especially in policymaking, where outcomes are determined by many actors and a wide range of motivations (Oliver et al. 2014; Smith 2013a). Therefore, little is known about the determinants and conditions of the conceptual impact of science. This is a major shortcoming given how important conceptual impact is. If scientific research generates conceptual impact, it can shift the scope of issues that are considered relevant, the appropriate means to address them, the important stakeholders to consult and the sources of knowledge (Estabrooks 1999). Conceptual impact also influences the long-term 'knowledge creep', whereby policymakers are sensitised to important issues and informed about emerging policy problems (Weiss 1982; Weible et al. 2010).

Understanding the conditions for conceptual impact means considering a cognitive dimension: how policymakers think and which factors influence their reflections on the nature of policy problems. We based our conceptualisation on reflexive/discursive institutionalism. 


\section{Theoretical Foundations}

Reflexive (Edler 2003) or discursive institutionalism (Schmidt 2008, 2010, 2012, 2002) is a political science approach that captures cognitive and normative dimensions that influence the process through which scientific knowledge generates impact on policymaking. The epistemological and ontological approach of discursive institutionalism underpins our framework.

\section{Reflexive/Discursive Institutionalism}

In traditional neo-institutional analysis, change is thought to be brought about through rational calculation in given incentive structures and fixed preferences (rational choice institutionalism), changes in contextual settings over time within historical paths (historical institutionalism) or through evolutionary change in allencompassing social norms (sociological institutionalism). These three institutionalist approaches build upon specific ontological understandings of what determines change and can be applied to specific empirical cases. However, they all neglect individual and organisational sense-making, a major underlying property of decision-making. This refers to the gathering of credible information and data and theoretical concepts to make sense of them.

Reflexive institutionalism was developed to address this sense-making and its role in policy change. It asserts that what actors define as problems, what they consider possible solutions, and how they see their interests are open to change. Thus, change comes about as a result of cognitive processes based on thinking about ideas (Béland and Cox 2010). Ideas can change interest perceptions, alter existing institutional paths and overcome boundaries set by pervasive social norms. Beliefs can "provide the recipes, guidelines, and maps for political action and serve to justify policies and programs by speaking to their interest-based logic and necessity" (Schmidt 2008: 306). This approach is anchored in a broader ideational movement in the social sciences that discusses the role of ideas in understanding the policy process (Blyth 1997; Fischer and Gottweis 2012; Seeleib-Kaiser and Fleckenstein 2007; Béland and Cox 2010). Most of these authors agree that there are different types of ideas with varying degrees of influence on policymaking (Beland 2005). A common approach and the most appropriate for our purpose is to distinguish three levels of ideas: ideas concerning the nature of a problem, the nature of the solution, and ideas that shape the overall 'public philosophy' (Heclo 1986), i.e. the public's understanding of the role of government vis-à-vis certain issues.

Vivien Schmidt elaborated the ideational institutional approach and coined the term 'discursive institutionalism', which emphasises the importance of both the substantive content (e.g. scientific evidence) and the interactive process (Schmidt 2017: 5) to capture the influence of ideas on policy change (Schmidt 2008: 303). Schmidt's distinction between coordinative and communicative discourse is especially important for our context. Both kinds of discourse provide different channels for scientific ideas to be transported, transformed and absorbed (Schmidt 2008). Coordinative 
discourse evolves within the policymaking process to establish the necessary level of consensus. Discourse participants comprise all the actors involved in the creation, elaboration and justification of policy ideas. This discourse includes technical experts and is shaped by epistemic communities (Haas 2009) arranged around shared bodies of knowledge. As these communities adhere to certain basic epistemological and ontological truths, they influence the likelihood with which new ideas are transmitted and accepted. ${ }^{2}$ Epistemic communities are cross-organisational, linking academia, think-tanks and policymaking bodies. However, ideational brokerage may still be required (Parsons 2002: 174). Epistemic communities can support 'advocacy coalitions' (Sabatier 1988), which combine material interests and normative beliefs to pro-actively influence policy decisions.

Communicative discourse connects the political sphere and the general public. It serves to legitimise political decisions or trigger policy change through public pressure. Important intervening factors here are the formal institutional context, the polity, and the political culture. The two discourse types interact in many ways. Coordinative discourse, fed also by scientific arguments, links to the public narrative and vice versa. The power of the epistemic community within coordinative discourse may add legitimacy when engaging with the general public (Edler 2003). Conversely, communicative discourse may exert normative power, against which cognitive beliefs in coordinative discourse cannot persist (Schmidt 2002).

Discursive institutionalism provides an entry point to understanding the existing - and changeable - institutional conditions in policy organisations that interact with, absorb and transform scientific knowledge. It considers the ability of actors to make sense of ideational content. Organisational systems of meaning and understanding, often referred to as background knowledge, act as an ideational filter and interpretative device. Organisations (and the individuals within them) employ these background ideational abilities when encountering new ideas. These abilities influence the extent to which these new ideas exert conceptual influence within policymaking organisations (Schmidt 2008). Extending the discursive institutionalist theorising to consider the extent and ways in which the institutional context can act as an intervening variable for the impact of (scientific) ideas on policy. For our framework to conceptualise the impact of scientific knowledge on policymaking, we conclude that:

(1) We use established approaches to understand policy change as a result of ideational processes

(2) Ideas should be distinguished on three levels (broader "Zeitgeist", problem definition, solutions), each with their own specific implication for policy change

(3) We need to understand the origin of ideas as well as how they evolve in order to understand their conceptual effects on policymaking organisations

\footnotetext{
${ }^{2}$ Haas developed this model in the context of international organisations and focused on the agency of epistemic communities and their interest in promoting certain ideas. However, the basic proposition, the cross-organisational epistemic community as a transmission belt for (scientific) ideas, remains an important element of a framework for how scientific ideas influence policymaking.
} 
(4) We can distinguish different kinds of ideational discourses with their own logics

(5) We need to consider the (pre-)existing and co-evolving institutional and ideational conditions in policymaking organisations to understand how external ideas influence them.

\section{Three Elements of Institutions}

We now turn to what we see as a major gap in the discursive institutionalist approach: its elaboration of background ideational abilities is too limited to understand how institutional conditions within policymaking organisations affect participants in the ideational discourse. We suggest that an organisation's background ideational abilities can be analytically accessed by distinguishing three elements of institutions: regulative, socio-normative and cognitive, as suggested by Richard Scott (2014). These elements encompass both structures and processes and can be implicit or explicit. They emerge from sustained social interaction, and are interdependent and interwoven in practice.

Regulative institutional elements are established by instructions that influence human behaviour via a system of sanctions and rewards. These can be legal prescriptions or formal rules. In organisations, regulative elements encompass formal authority structures, incentives, bonuses, promotions, and also penalties and fines. Within policymaking, formal and legal policy development processes rest on the regulative institutional pillar, for example, the requirement to use the best available evidence when developing policy.

Normative institutional elements reflect shared expectations and social obligations regarding behaviour in certain circumstances. Encompassing values and roles, normative elements explain how actors interpret social context in order to take an 'appropriate' course of action to achieve their goals (March and Olsen 2011). These common frames of reference allow actors to navigate social life by anticipating the behaviour of others. In our context, normative elements influence policymakers' notions about what research is considered robust and reliable.

Cognitive institutional elements encompass meanings attached to social action, symbols, identities, causal connections, and scripts. They are taken for granted, rarely contested and sometimes not rationalised. They make up the 'natural order' in which actors operate, and its 'constitutive rules' (Searle 1969), creating shared frames of meaning in social life. Cognitive processes influence policymakers' sense of trust when they see research presented in a familiar way, or using familiar epistemic devices.

We can now combine the theoretical foundations. Discursive institutionalism offers a conceptualisation of the policy development process as an ideational deliberation between the actors engaged in coordinative discourse (Schmidt 2008). The mechanisms through which actors develop and/or change their ideas about the nature of problems, the solution space and the overall role of governance are captured by the notion of background ideational ability. Organisational systems of meaning, consisting of cognitive, normative and regulative elements, influence policymakers' ability and willingness to be influenced by new ideas. The three elements 


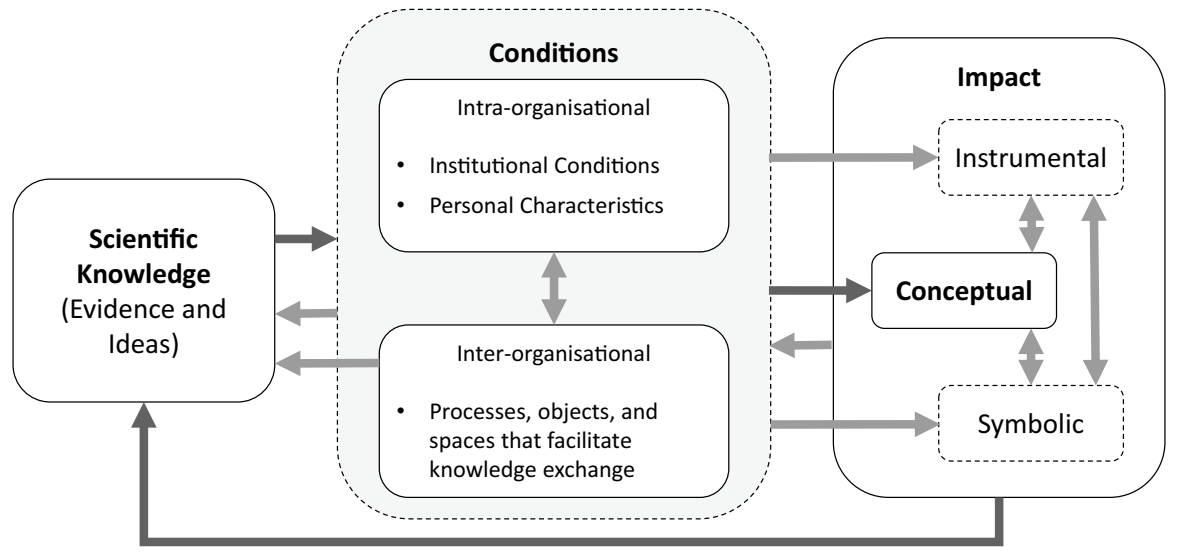

Fig. 1 Institutional conditions influencing the impact of scientific knowledge on policy - expanded framework ( source: authors)

of institutions not only explain how organisational environment affects cognitive dynamics, but can also explain how ideas already present in organisations can move closer or further away from their 'deep core' (Sabatier 1988) background philosophies. Regulative, normative and cognitive legitimacy mechanisms influence how ideas are observed, filtered and made sense of by actors (Cashmore and Wejs 2014). Some ideas are considered credible, while others do not pass institutional filters.

The next section applies the ideational institutionalist approach to explain the conceptual impact of science on policymaking. While conceptual impact necessarily implies change on at least one of the three ideational levels, scientific ideas that enter policy organisations may not align with all three intuitional elements, which will affect how policymakers interact with them. Our conceptual framework captures the conditions influencing these dynamics in a structured way.

\section{Conceptual Framework}

\section{Institutional Conditions and Ideation in Policymaking}

The framework documents the institutional conditions in policymaking organisations that influence the conceptual dimensions of the policy development process. It consists of three major components: the properties of scientific knowledge, the organisational and institutional conditions, and the types of impact. These mutually influence one another (Fig. 1). The framework is informed by discursive institutionalist research that emphasises the role of ideas in policymaking (see above) and organisational institutionalist research that theorises about the various institutional elements that affect knowledge transfer, acquisition, and absorption (see above).

Component one, scientific knowledge, includes research results and underlying scientific ideas. The characteristics of scientific knowledge and the pathways via which it reaches policymakers affect its uptake. Non-codified knowledge transfer, 
e.g. via personal communication, is more likely to influence policymakers conceptually (Molas-Gallart and Tang 2011). The reputation of the authors and organisations producing the research (Olmos-Peñuela et al. 2014), whether there is contestation or consensus in the scientific community (Shackley and Wynne 1996), and the social context surrounding the research process (Kessler and Glasgow 2011; Stirling 2007) are also significant. These aspects are largely beyond this paper's scope, since our focus is on conditions on the user side.

Component three, the impact of science, uses the conventional typology distinguishing impact into conceptual, instrumental, and symbolic (see Section "Conceptual Impact"). Although our framework focuses on identifying the conditions for conceptual impact, the three types are interrelated. The impact pathway itself is rarely linear and rarely results in just one type of impact (Joly et al. 2015).

The framework's main contribution is its focus on component two, the institutional conditions of policy 'user' organisations that influence the process through which scientific knowledge has impact on policy. These conditions are presented in Table 1 and coded as follows. Institutional conditions within policy organisations are termed 'intra-organisational conditions' (I). The broader conditions of institutional fields they are embedded in are termed 'inter-organisational conditions' (II). These are essential to understand the flow and co-development of scientific knowledge between organisations. For both types, we differentiate between regulative (R), normative $(\mathrm{N})$ and cognitive $(\mathrm{C})$ institutional elements. The framework also recognises individuals as 'thinking' agents capable of reflecting about new ideas and evidence $(\mathrm{P})$. The conditions influence the background ideational abilities of scientific knowledge users. The next sections substantiate and further qualify the framework components.

\section{Intra-Organisational Conditions}

Intra-organisational conditions encompass institutional structures and processes within policy user organisations, such as guidelines, values, management structures and practices of knowledge acquisition. We distinguish between regulative elements that describe formal instructions for the use of research, normative elements relating to organisational values and strategy, and cognitive elements that cover aspects such as organisational philosophy, assumptions, habits and scripts. Interrelated in practice, these elements exert different kinds of influence on how the organisation deals with scientific knowledge.

Regulative elements provide extrinsic motivation for policymakers to engage with science. If there is a mandate to consult research when developing new policies (IR3), policymakers are compelled to seek it. Exposure to research then increases the likelihood that policymakers engage with it, opening up opportunities for impact. Overall, the capacity to support engagement by allocating resources, setting up infrastructure and creating dedicated staff roles is widely recognised as the foundation for the effective use of science in policy (Olmos-Peñuela et al. 2014).

Formally established research units, and horizontal and vertical communication channels (IR1) reinforced by a monitoring and incentives system (IR4) 


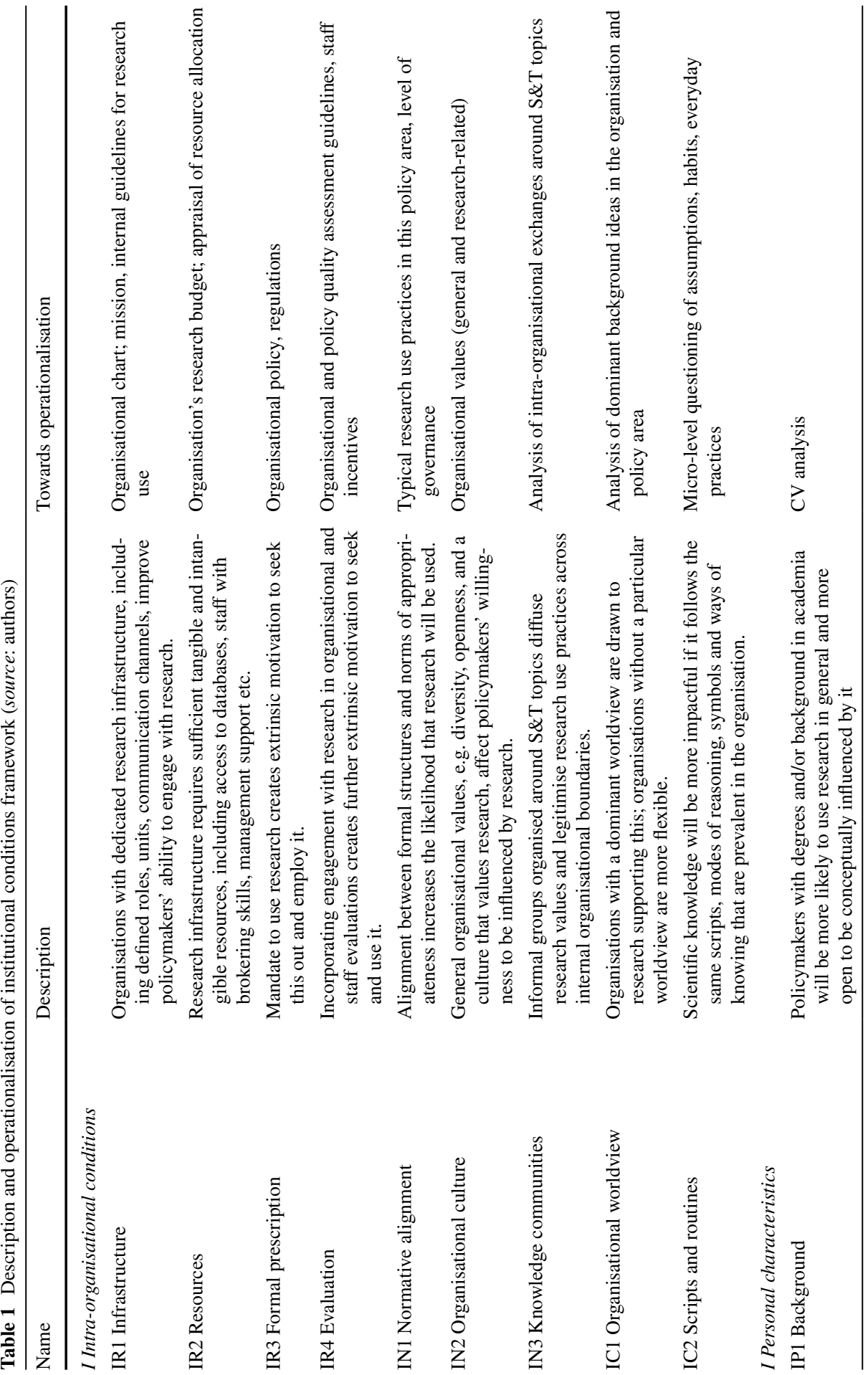




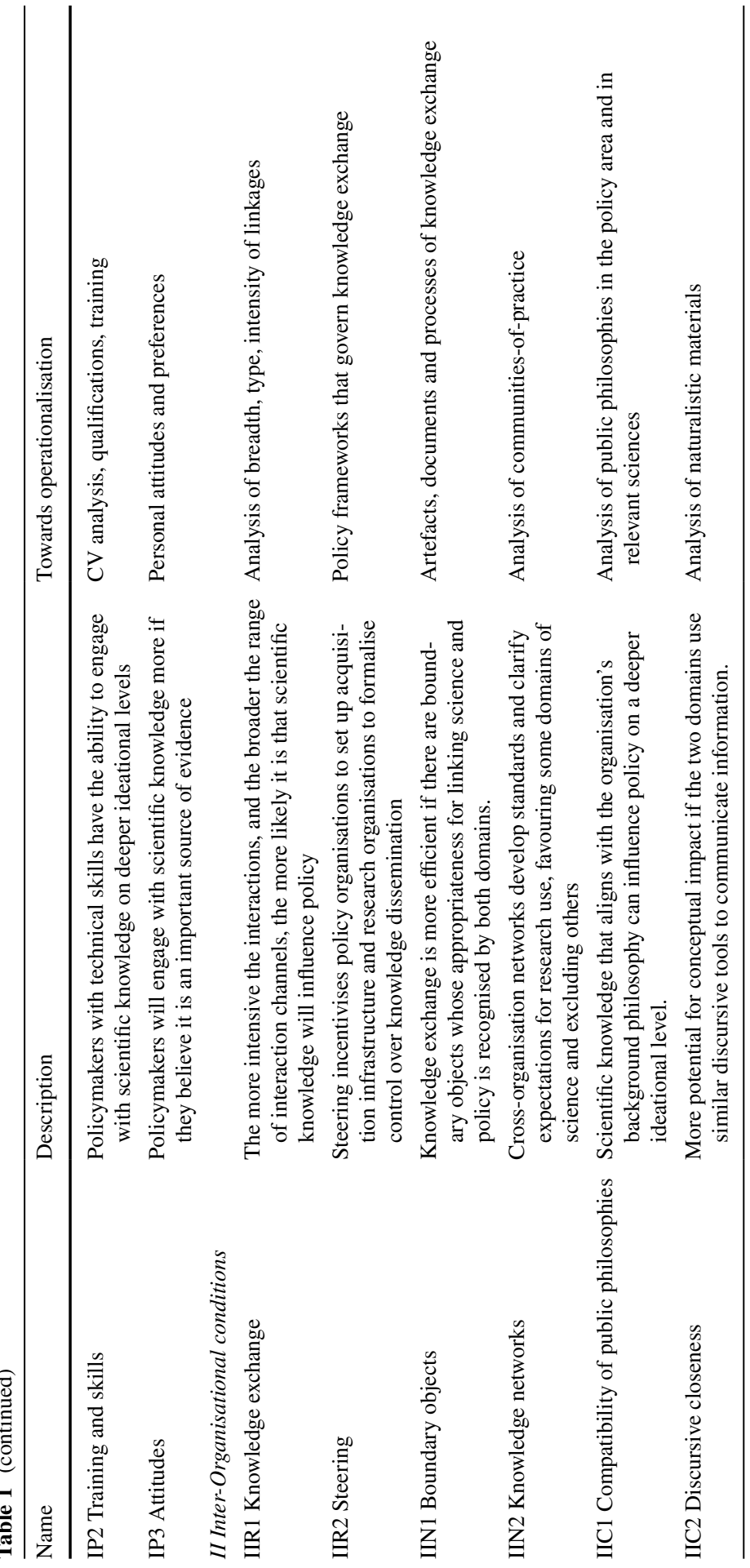


constitute essential research infrastructure to support decision-making (Nutley et al. 2007; Makkar et al. 2015). Scientific research is more likely be used if the use processes are clearly defined (Armstrong et al. 2013). Organisations that formally structure their research utilisation, e.g. by setting up in-house analytical units, knowledge brokers or scientifc advisers, use research more effectively than those that do not (Topp et al. 2018; Belkhodja 2014). This infrastructure requires sufficient funding and specialised intangible resources (IR2), including staff who can both understand complex science and communicate it effectively to non-specialists (Holmes and Clark 2008).

Formal structures can only be effective if they are acknowledged as necessary, appropriate and legitimate, which highlights the role of normative institutional conditions (Weiss et al. 2008). Policymakers' attitudes will be influenced by the general perception of research in their work area, how and to what extent it is used by others in similar positions (IN1). Policymakers in environments with organisational culture (IN2) that is receptive to new ideas and approaches will be more likely to consider multiple different types of knowledge (Hammami et al. 2013). Openness and exploration of new knowledge sources (March 1991) are organisational values that may prompt policymakers to look for evidence beyond familiar sources. Notions of appropriateness and best practices are diffused within the organisation via knowledge communities (IN3): groups of like-minded employees, who organise themselves around thematic topics. These communities can boost the value assigned to research, legitimise and normalise the use of scientific knowledge across different organisational units and levels of authority (Currie and Suhomlinova 2006). They also contribute to learning to use scientific research effectively in their specific organisational setting (Andereggen et al. 2013).

Cognitive institutional elements provide the shared ideational foundation to these activities and processes. For instance, organisational philosophy (IC1) underpins the reasons for the organisation's existence, its fundamental worldview. Policymaking is made sense of against the backdrop of these 'deep core' ideas. If scientific knowledge does not align with the organisation's dominant worldview, this can obstruct knowledge absorption. Research will not be considered relevant or legitimate (Boswell and Hampshire 2017; Rein and Schön 1993). Conversely, organisations with more than one worldview are more open to diverse kinds of knowledge.

Cognitive institutional elements also encompass micro-level behaviour: scripts, routines and assumptions (IC2). Using research is habitual to a large extent (van der Arend 2014) and influenced by stereotypes and cultural norms (Brownson et al. 2009). Policymakers may favour certain types of knowledge, methods, and ways of communicating, which shape the possibilities for certain kinds of scientific knowledge to enter policy processes. For example, economic reasoning is pervasive in policy and underpinned by the institutional logics of quantification prevalent in broader society (Espeland and Stevens 2008). Economic and statistics research are therefore likely to be considered seriously in many policy organisations, because they operate with the same style of reasoning, and employ familiar symbols and instruments that policymakers prefer to use as evidence (Hirschman and Berman 2014). 


\section{Inter-organisational Conditions}

Inter-organisational conditions are shaped by the relationships between organisations in science and policy domains. Inter-organisational interactions may match and validate the policy organisation's structures and processes as legal, appropriate or true or highlight contradictions (Seo and Creed 2002). Regulative inter-organisational conditions are primarily formally defined channels and tools for knowledge exchange. Normative and cognitive conditions explain how mutual understanding is developed at science-policy interfaces.

Regulative conditions encompass institutional structures for the production and evaluation of knowledge and formal knowledge transfer channels between science and policy (IIR1). Overall, the intensity of linkages has been directly associated with policymakers' propensity to engage with scientific research (Belkhodja 2014). The scale and scope of steering (IIR2) is also a significant factor; the 'gap' between research and policy is often seen as the rationale for intervention to improve knowledge exchange (Brownson et al. 2006; Avey and Desch 2014). Funders routinely incorporate societal impact considerations into ex-ante and ex-post project evaluations to steer researchers' behaviour (Wallace and Rafols 2015; Meyer 2011). Efforts are also made to identify the most effective ways of incorporating research evidence into policy (Grimshaw et al. 2012; Green and Glasgow 2006; Brownson and Jones 2009; Sanderson 2002; Head 2016). These discussions have pushed policy organisations to put knowledge exchange on their agendas and led to rich experimentation concerning the modes and formats of science-policy knowledge transfer (Bremer and Meisch 2017; Knight and Lyall 2013).

Normative institutional elements explain how shared notions develop about which knowledge is considered credible (Cash et al. 2003). Scientific research is usually too abstract and technically complex to be used directly in policymaking and needs to be adapted by boundary-spanning actors (Sarkki 2017; Reinecke 2015). Normative elements underpin the appropriate format for the boundary object (IIN1) and how to organise the boundary spanning process (Hoppe et al. 2013; Turnhout et al. 2007). These perceptions emerge in cross-organisational knowledge networks (IIN2) of scientists and policymakers, who act together to advocate their preferred policy issues and solutions (McCright and Dunlap 2010; van der Sluijs et al. 1998; Smith 2013b; Edler and James 2015). These stakeholders may interact in dedicated meeting places as a community of practice (Amin and Roberts 2008).

One example is how usable knowledge is developed. Usable knowledge is contextual: it is scientific knowledge that can be absorbed and applied in policy without further translation - a boundary object shaped by the expectations of both scientists and policymakers about each other's work via negotiation and expectation management (Stilgoe et al. 2013). In healthcare, for instance, researchers have argued that systematic reviews constitute better usable knowledge than individual research results, because they aggregate the outcomes of many standardised empirical studies and have high external validity (Green and Glasgow 2006; Grimshaw et al. 2012). Healthcare policymakers are correspondingly keener to use systematic reviews than practitioners in other domains (Bedard and Ouimet 2017). However, such commonly accepted boundary objects can also lock out research not attributed the appropriate 
level of legitimacy. Leach and Scoones (2013) use the case of zoonotic disease models to demonstrate that certain scientific models are "co-constructed with particular policy narratives about the disease problem" (15). As these models were the outcome of mutual knowledge development and exchange among networks of research and policy organisations, it was easier for them to gain traction when policymakers had to deal with a disease outbreak. Alternatives were only considered once these models were no longer able to provide reliable predictions.

Cognitive inter-organisational conditions primarily reflect the importance of the compatibility of background ideas in science and policymaking organisations (IIC1). Dominant public philosophies determine the way issues are framed, arguments built and solutions selected. If scientific knowledge was produced within a different public philosophy than the one policymaking organisation operates it, policy officials will be unable to use research due to basic, irreconcilable differences in world views that hamper meaningful mutual understanding (Lindvall 2009). For example, Schmidt (2016) argues that industrialised countries have been unable to deal with recent economic crises, because neoliberalism, the dominant background philosophy, limits the breadth of analysis and variety of instruments 'imaginable' in economic policy. Scientists and policymaking organisations share a neo-liberal majority view, and heterodox scientific organisations with competing views are unable to get throughthe neo-liberal filter. Carstensen and Matthijs (2018) observe that disputes leading to policy change tend to happen within paradigms, not between them, as the result of a stream of individual decisions that gradually alter the dominant paradigm. Therefore, scientific ideas which deviate from existing thinking in policymaking can be influential as long as they are compatible with the dominant public philosophy and the existing policy architecture.

Cognitive institutional conditions further include elements that evolve into knowledge translation scripts over time (Kuruvilla et al. 2006). The discursive proximity (IIC2) between domains affects the extent to which they can conceptually influence each other. For example, policymakers are more likely to consider evidence written in a familiar language (Upham and Dendler 2015), presented in a familiar format through a trusted, expected channel. These cognitive differences between what policymakers are comfortable with and what researchers are able to provide are cited as a key barrier to impact (Weichselgartner and Kasperson 2010).

\section{Individuals in Organisations}

Although institutional conditions influence policymakers' background ideational abilities, individuals also have agency to consider scientific knowledge independently during the policy development process. From the discursive institutionalist standpoint, individual reflection and subsequent collective deliberation are two key components of policy change. We distinguish three personal characteristics 
of policymakers that affect the extent to which they are influenced by scientific knowledge ${ }^{3}$.

First, policymakers with advanced degrees and/or work experience in research (IP1) are much more likely to be conceptually influenced by science (Amara et al. 2004). They are more exposed to scientific knowledge in in their networks, are more inclined to trust the standards of scientific knowledge production, and can bridge the cognitive and cultural gap between ideas in science and policy. Second, policymakers with the technical skills to read and appraise scientific research (IP2) are more likely to understand its core ideas and assumptions and engage with it on deeper ideational levels. Third, policymakers' individual attitudes (IP3) towards science, its value and role in the policy development process determine their willingness to seek out and use relevant research (Jbilou et al. 2007). Here, it is important to consider differences between policy areas that often require S\&T evidence (e.g. healthcare), those that primarily use data as evidence, and those with hotly contested topics where policymakers need to engage in value-based debates.

\section{Institutional Inter-dependencies}

So far, we have described the three institutional dimensions at the organisational and individual level in relative isolation. However, in "most empirically observed institutional forms, we observe not one, single element at work, but varying combinations of elements" (Scott 2008: 62). This means that "if pillars are aligned, the strength of their combined forces can be formidable" (ibid). In other words, the degree of alignment determines the way and extent to which they influence organisational and individual behaviour. The number of possible combinations of elements in all three pillars is endless and how pillars align is an empirical question, but our framework enables us to recognise the inter-dependencies of institutional dimensions.

The ability, willingness and readiness to understand the nature of scientific knowledge, interpret its outcome and assign credibility not only depend on "rigorous" scientific approaches and appropriate dissemination activities. They also depend on the interplay of regulative, cognitive and normative conditions within policymaking organisations and between policy and research organisations. Conceptual impact will be limited no matter how strong the scientific evidence or how clearly it is communicated, if institutional conditions that enable impact are missing. The lack of material resources, such as access to scientific publications, or of time to identify relevant research can inhibit policymakers' engagement with scientific knowledge, even if there are strong normative demands to use such knowledge in policy.

Time is another relevant factor when discussing institutional dimensions. Institutions are persistent structures, but the durability of the different institutional elements varies. Cognitive elements in particular form over a period of time as ideas gradually sediment

\footnotetext{
3 Naturally, the characteristics and attitudes of individual scientists are also important in generating impactful research (see D'Este et al. 2018). However, the focus here is on individuals in policymaking organisations.
} 
to the 'deep core' of organisations and become the taken-for-granted and unarticulated (Eleveld 2016). The difference in depth between the institutional pillars becomes apparent if the organisation undergoes change. Regulative changes, such as new investments and instructions or the recruitment of skilled staff, can be made relatively quickly, but it will take (often a significant amount of) time for change to occur at deeper levels.

\section{Institutional Conditions in the Policy Process}

Finally, we acknowledge that the potential impact science has on policy will change throughout the policy process. Our concept follows the well established, simplified and stylised multi-stage model of the policy process (Lasswell 1956). Policy analysts interested in the role of knowledge and evidence (Strassheim 2018; Perl 2020) have used this model to highlight the different needs of policymakers for external knowledge and evidence in the "political capacity" concept.

Table 2 indicates the need for knowledge and information during different stages of the policymaking process and how the need for scientific knowledge changes. In early stages, broad knowledge is needed to support agenda-setting. This is where issues are legitimised and constructed as problems (Perl 2020), and where ideas, including external scientific ideas and knowledge, most strongly conceptually influence the policy process (Fischer and Forrester 1993; Sabatier 1988). In principle, the defintion and framing of the policy issue at hand is open and the policy formulation process benefits from alternative analyses. Thus, the intra-organisational and inter-organisational conditions need to enable access to diverse sources of knowledge, and policymakers must have sufficient absorptive capacity to make sense of different scientific data and to interpret issues. Further, the normative expectation in an organisation needs to encourage using diverse scientific knowledge as an important source in the initial framing of an issue.

In later stages of policy development, more standardised capabilities and techniques are needed to support implementation and policy learning. The interface to external knowledge sources is thus narrower, focused on technical support, and the absorptive capacity of policymakers may be more specialised. The need for broader knowledge opens up again at the evaluation stage, where reflection is needed on the achievements and shortcomings of the previous policy cycle.

Howlett (2009) claims that the failure to cope with the knowledge challenges at the different stages of policy development stems from poor capabilities and systems to use of knowledge and can be improved through better knowledge management. We concur, but stress that in order to do so we need to start with better analysis of the conditions that influence the use of external knowledge at those different stages.

\section{Contributions and Policy Implications}

Our framework focuses on the institutional conditions in 'user' organisations that influence the conceptual impact of scientific knowledge. While we recognise that the actual policy development process is dynamic, messy and complex, there is a need to rebalance the recent excessive emphasis on the roles, activities and efforts 
Table 2. Scientific knowledge challenges and needs during the policy process.

\begin{tabular}{lcc}
\hline Policy stage & Common Knowledge Challenge & Knowledge need and entry point \\
\hline Agenda setting & $\begin{array}{c}\text { Need and legitimacy for public action } \\
\text { and its direction. Unclear or excessive } \\
\text { policy goals }\end{array}$ & $\begin{array}{c}\text { Understanding the nature of an issue } \\
\text { and its formulation as a policy } \\
\text { problem }\end{array}$ \\
Policy formulation & $\begin{array}{c}\text { Investigate causes and probable effects } \\
\text { of policy alternatives to deal with } \\
\text { "wicked" problems }\end{array}$ & $\begin{array}{c}\text { Sufficient insights into causation } \\
\text { mechanisms and alternative solu- } \\
\text { tions }\end{array}$ \\
Decision-making & $\begin{array}{c}\text { Failing to anticipate adverse or unin- } \\
\text { tended policy consequences }\end{array}$ & $\begin{array}{c}\text { Cost-benefit and risk assessment of } \\
\text { different policy options. }\end{array}$ \\
Policy implementation & $\begin{array}{c}\text { Overcoming lack of funding, principal- } \\
\text { agent problems, oversight failures etc. }\end{array}$ & $\begin{array}{c}\text { Monitoring and inspection systems, } \\
\text { learning support }\end{array}$ \\
Policy evaluation & Appropriate learning, functional moni- & $\begin{array}{c}\text { Adequate measurement and reflec- } \\
\text { tion techniques }\end{array}$ \\
\hline
\end{tabular}

Source: based on Howlett (2009), Strassheim (2018), modified by the authors

of scientists by refocusing on organisational filters on the user side. The framework combines a discursive institutionalist understanding of the nature and mechanisms of ideational dynamics in policymaking with organisational institutionalist approaches to capture absorptive conditions within and between organisations. Combined with characteristics of reflexive individual policymakers, these are the elements required to understand the nature and extent of conceptual impact.

To the best of our knowledge, this perspective, and the finely grained differentiation of the ideational and institutional dimensions is the first attempt to spotlight the conceptual impact of science on policy. Early in the paper, we criticised that previous research honed in on the observable uses and impacts of science, and tended to neglect the less-observable pathways, activities and conditions for conceptual impact. If we accept that how policymakers interpret the world and define solutions is a critical dimension in the policymaking process, we also must acknowledge the importance of the ideational dimension. We employed a reflexive institutionalist lens to make sense of how ideas exert influence. It helps us to understand when and how scientific ideas and evidence influence perceptions of the nature of problems and possible solutions, i.e. when conceptual impact occurs. We also recognise that the discourse, through which scientific knowledge enters policy spaces, and the conditions under which it is processed are also critical for the impact of science on policy.

The framework is not intended to substitute the existing literature, but to extend and enrich it. The framework outlines the micro-foundations for understanding mechanisms of the use of scientific knowledge in policy via a multi-dimensional and inter-linked conceptualisation of the user conditions. It enables what Sarewitz and Pielke (2007) called a "demand-side assessment" (12): a structured analysis of the conditions and behaviours on the side of scientific research 'users'. The third column in Table 2 points towards the framework's operationalisation. We suggest a case study methodology for empirical research. Additionally, research utilisation surveys could be helpful to analyse the conceptual use of research. 
We conclude the paper by returning to a key initial observation in the introduction. The current calls for mission orientation across the OECD imply that science, technology and innovation policy can help find solutions to societal problems. However, there is widespread agreement that different policy areas need to be aligned to accomplish this. This means that problem framings and the policies to develop solutions need to be underpinned by evidence that can be understood and acknowledged by diverse organisational actors. This goes beyond traditional policy coordination. It is, in a very fundamental sense, a question of inter-organisational ideational alignment and co-evolution.

Defining a mission that spans multiple policy areas, such as "plastic-free oceans", "carbon-free cities", or "automated driving" requires sound scientific underpinning. Applying our framework, it means a "coordinative discourse" for policymaking that considers the pre-existing, historically path-dependent ideational backgrounds of diverse policy organisations. Their ideational alignment that enables science to have an impact on the overall mission needs careful consideration. Certain bodies of evidence or even basic scientific ideas may be compatible with the background of one key ministry, but incompatible with another. Similarly, there will almost inevitably be different opinions about the extent to which scientific knowledge can be used to define the problem, as rationale for policy intervention, and to define criteria for assessment.

Our perspective suggests it is imperative to be aware of the critical dimensions within and between organisations when mobilising science for missions, from framing the mission to identifying problems and envisaging solutions. Inter-organisational conflicts in the pursuit of missions may be much less a result of traditional power games than problems with ideational interaction and alignment. Accomplishing complex missions will not work without support from science. Policy organisations must inspect their own conditions for the uptake of scientific knowledge if they want science to play its role effectively. For academics seeking to understand the impact of science on policy, it means opening up to ideational approaches.

Acknowledgements We acknowledge the insightful comments of Magnus Gulbrandsen, Jordi MolasGallart, Richard Woolley, Rainer Frietsch and the two anonymous reviewers who helped us shape and improve this paper.

Funding Open Access funding enabled and organized by Projekt DEAL. This research is supported by the Research Council of Norway under the FORINNPOL Centre OSIRIS, coordinated by the University of Oslo. The Grant Number is 256240.

Conflict of interest The authors declare no conflict of interest.

Open Access This article is licensed under a Creative Commons Attribution 4.0 International License, which permits use, sharing, adaptation, distribution and reproduction in any medium or format, as long as you give appropriate credit to the original author(s) and the source, provide a link to the Creative Commons licence, and indicate if changes were made. The images or other third party material in this article are included in the article's Creative Commons licence, unless indicated otherwise in a credit line to the material. If material is not included in the article's Creative Commons licence and your intended use is not permitted by statutory regulation or exceeds the permitted use, you will need to obtain permission directly from the copyright holder. To view a copy of this licence, visit http://creativecommons.org/licen ses/by/4.0/. 


\section{References}

Almeida, Celia, and Ernesto Báscolo. 2006. Use of research results in policy decision-making, formulation, and implementation: a review of the literature. Cadernos De Saúde Pública 22: 7-19.

Amara, Nabil, Mathieu Ouimet, and Rejean Landry. 2004. New evidence on instrumental, conceptual, and symbolic utilization of university research in government agencies. Science Communication 26: 75-106.

Amin, Ash, and Joanne Roberts. 2008. Knowing in action: Beyond communities of practice. Research Policy 37: 353-369.

Andereggen, Stefan, Frank Andreas Zoller, and Roman Boutellier. 2013. Sharing Research Equipment to Bridge Intraorganizational Boundaries. Research-Technology Management 56: 49-57.

Armstrong, Rebecca, et al. 2013. Knowledge translation strategies to improve the use of evidence in public health decision making in local government: intervention design and implementation plan. Implementation Science 8(1): 1-10.

Avey, Paul C., and Michael C. Desch. 2014. What Do Policymakers Want From Us? Results of a Survey of Current and Former Senior National Security Decision Makers. International Studies Quarterly 58: 227-246.

Bedard, Pierre-Olivier, and Mathieu Ouimet. 2017. Awareness and use of systematic literature reviews and meta-analyses by ministerial policy analysts. Canadian Public Administration-Administration Publique Du Canada 60: 173-191.

Beland, Daniel. 2005. Ideas and social policy: An institutionalist perspective. Social Policy \& Administration 39: 1-18.

Béland, Daniel, and Robert H. Cox. 2010. Ideas and politics in social science research. Oxford: Oxford University Press.

Belkhodja, Omar. 2014. Knowledge Utilization in Canadian Health Service Organizations: A Path Analysis. International Journal of Public Administration 37: 339-352.

Blyth, Mark. 1997. "Any more bright ideas?” The ideational turn of comparative political economy. Comparative Politics 29: 229-250.

Boon, Wouter, and Jakob Edler. 2018. Demand, challenges, and innovation. Making sense of new trends in innovation policy. Science and Public Policy 45: 435-447.

Borgenschneider, Karen, and Tom Corbett. 2010. Evidence-based policy making. New York: Routlege.

Bornmann, Lutz. 2013. What is societal impact of research and how can it be assessed? A literature survey. Journal of the American Society for Information Science and Technology 64: 217-233.

Boswell, Christina, and James Hampshire. 2017. Ideas and agency in immigration policy: A discursive institutionalist approach. European Journal of Political Research 56: 133-150.

Bozeman, Barry, and Daniel Sarewitz. 2011. Public Value Mapping and Science Policy Evaluation. Minerva 49(1): 1-23.

Bremer, Scott, and Simon Meisch. 2017. Co-production in climate change research: reviewing different perspectives. Wiley Interdisciplinary Reviews: Climate Change 8: e482.

Broström, Anders, and Maureen Mckelvey. 2017. Engaging Experts: Science-Policy Interactions and the Introduction of Congestion Charging in Stockholm. Minerva 56(2): 183-207.

Brownson, Ross C., Jamie F. Chriqui, and Katherine A. Stamatakis. 2009. Understanding evidence-based public health policy. American Journal of Public Health 99: 1576-1583.

Brownson, Ross C., and Ellen Jones. 2009. Bridging the gap: translating research into policy and practice. Preventive Medicine 49: 313-315.

Brownson, Ross C., Charles Royer, Reid Ewing, and Timothy D. Mcbride. 2006. Researchers and policymakers - Travelers in parallel universes. American Journal of Preventive Medicine 30: 164-172.

Caplan, Nathan. 1979. The two-communities theory and knowledge utilization. American Behavioral Scientist 22: 459-470.

Carstensen, Martin B., and Matthias Matthijs. 2018. Of paradigms and power: British economic policy making since Thatcher. Governance 31(3): 431-447.

Cash, David W., et al. 2003. Knowledge systems for sustainable development. Proceedings of the National Academy of Sciences 100: 80-86.

Cashmore, Matthew, and Anja Wejs. 2014. Constructing legitimacy for climate change planning: A study of local government in Denmark. Global Environmental Change 24: 203-212. 
Contandriopoulos, Damien, Marc Lemire, Jean-Louise Denis, and Emile Tremblay. 2010. Knowledge Exchange Processes in Organizations and Policy Arenas: A Narrative Systematic Review of the Literature. Milbank Quarterly 88: 444-483.

Crona, Beatrice I., and John N. Parker. 2011. Network Determinants of Knowledge Utilization: Preliminary Lessons From a Boundary Organization. Science Communication 33: 448-471.

Currie, Graeme, and Olga Suhomlinova. 2006. The Impact of Institutional Forces Upon Knowledge Sharing in the UK NHS: The Triumph of Professional Power and the Inconsistency of Policy. Public Administration 84: 1-30.

D'Este, Pablo, Irene Ramos-Vielba, Richard Woolley, and Nabil Amara. 2018. How do researchers generate scientific and societal impacts? Toward an analytical and operational framework. Science and Public Policy 45: 752-763.

De Jong, S., K. Barker, D. Cox, T. Sveinsdottir, and P. Van den Besselaar. 2014. Understanding societal impact through productive interactions: ICT research as a case. Research Evaluation 23(2): 89-102.

De Rijcke, Sarah, Paul Wouters, Alex D. Rushforth, Thomas Franssen, and Bjorn Hammarfelt. 2016. Evaluation practices and effects of indicator use-a literature review. Research Evaluation 25(2): 161-169.

Donovan, C., and S. Hanney. 2011. The 'payback framework' explained. Research Evaluation 20(3): 181-183.

Donovan, Claire. 2011. State of the art in assessing research impact: introduction to a special issue. Research Evaluation 20: 175-179.

Edler, Jakob. 2003. How do economic ideas become relevant in RTD policy making? In Innovation Policies in Europe and the US: The New Agenda, eds. Peter Biegelbauer, and Susanna Borras. Ashgate: Aldershot.

Edler, Jakob, and Andrew D. James. 2015. Understanding the emergence of new science and technology policies: Policy entrepreneurship, agenda setting and the development of the European Framework Programme. Research Policy 44: 1252-1265.

Eleveld, Anja. 2016. The Role of Ideas in Policy and Institutional Change: A Comparison of the Open Functional Approach, Constructivism and Discourse Theory. Political Studies 64: 70-87.

Espeland, Wendy N., and Mitchell L. Stevens. 2008. A Sociology of Quantification. European Journal of Sociology 49: 401-436.

Estabrooks, C.A. 1999. The conceptual structure of research utilization. Research in Nursing \& Health 22(3): 203-216.

European Commission. 2018. Towards a mission-oriented research and innovation policy in the European Union.

Fischer, Frank, and Herbert Gottweis. 2012. The argumentative turn revisited: Public policy as communicative practice. Durham: Duke University Press. https://doi.org/10.1515/9780822395362.

Green, Lawrence W., and Russel E. Glasgow. 2006. Evaluating the relevance, generalization, and applicability of research: issues in external validation and translation methodology. Evaluation and the Health Professions 29: 126-153.

Grimshaw, Jeremy M., Martin P. Eccles, John N. Lavis, Sophie J. Hill, and Janet E. Squires. 2012. Knowledge translation of research findings. Implementation Sciences 7: 50.

Haas, Peter M. 2009. Introduction: epistemic communities and international policy coordination. International Organization 46: 1.

Hall, Peter A. 1993. Policy paradigms, social learning, and the state: the case of economic policy-making in Britain. Comparative Politics 25: 275-296.

Hammami, Hajer, Nabil Amara, and Rejean Landry. 2013. Organizational climate and its influence on brokers' knowledge transfer activities: A structural equation modeling. International Journal of Information Management 33: 105-118.

Hanney, Stephen R., and Miguel A. González-Block. 2009. Evidence-informed health policy: are we beginning to get there at last? Health Research Policy and Systems 7: 30 .

Head, Brian W. 2016. Toward More "Evidence-Informed" Policy Making? Public Administration Review 76: 472-484.

Heclo, Hugh. 1986. Reaganism and the Search for a Public Philosophy. Perspectives on the Reagan Years 40: $25-41$

Hessels, L.K., and H.V. Lente. 2010. The mixed blessing of Mode 2 knowledge production. Science, Technology \& Innovation Studies 6(1): 65-69. 
Hicks, Diana. 2012. Performance-based university research funding systems. Research Policy 41(2): 251-261.

Hirschman, Daniel, and Elizabeth P. Berman. 2014. Do economists make policies? On the political effects of economics. Socio-Economic Review 12: 779-811.

Holmes, John, and Rebecca Clark. 2008. Enhancing the use of science in environmental policy-making and regulation. Environmental Science \& Policy 11: 702-711.

Hoppe, Robb, Anna Wesselink, and Rose Cairns. 2013. Lost in the problem: the role of boundary organisations in the governance of climate change. Wiley Interdisciplinary Reviews: Climate Change 4: 283-300.

Howlett, Michael, et al. 2009. Studying public policy: Policy cycles and policy subsystems. Oxford University Press Oxford.

Jäger, Jill, and H. L. Ferguson (eds.). 1991. Climate change. Science, impacts and policy; Proceedings of the Second World Climate Conference. Cambridge: Cambridge University Press.

Jbilou, Jalila, Nabil Amara, and Rejean Landry. 2007. Research-based decision-making in Canadian health organizations: A behavioural approach. Journal of Medical Systems 31: 185-196.

Jennings, Edward T., and Jeremy L. Hall. 2012. Evidence-based practice and the use of information in state agency decision making. Journal of Public Administration Research and Theory 22(2): 245-266.

Joly, Pierre-Benoit, et al. 2015. ASIRPA: A comprehensive theory-based approach to assessing the societal impacts of a research organization. Research Evaluation 24: 440-453.

Kenny, Caroline, David C. Rose, Abbi Hobbs, Chris Tyler, and Jason J. Blackstock. 2017. The Role of Research in the UK Parliament, vol. One. London: UK, Houses of Parliament.

Kessler, Roger, and Russel E. Glasgow. 2011. A proposal to speed translation of healthcare research into practice: dramatic change is needed. American Journal of Preventative Medicine 40: 637-644.

Kingdon, John. 1984. Agendas, Alternatives, and Public Policies, vol. 45. Boston: Little, Brown.

Knight, Christine, and Catherine Lyall. 2013. Knowledge brokers: the role of intermediaries in producing research impact. Evidence and Policy 9: 309-316.

Kuhlmann, Stefan, and Arie Rip. 2018. Next-Generation Innovation Policy and Grand Challenges. Science and Public Policy 45: 448-454.

Kuruvilla, Shyama, Nicholas Mays, Andrew Pleasant, and Gill Walt. 2006. Describing the impact of health research: a Research Impact Framework. BMC Health Services Research 6: 134.

Landry, Rejean, Moktar Lamari, and Nabil Amara. 2003. The extent and determinants of the utilization of university research in government agencies. Public Administration Review 63: 192-205.

Leach, Melissa, and Ian Scoones. 2013. The social and political lives of zoonotic disease models: Narratives, science and policy. Social Science \& Medicine 88: 10-17.

Lindvall, Johannes. 2009. The Real but Limited Influence of Expert Ideas. World Politics 61: 703-730.

Lomas, Jonathan. 2007. The in-between world of knowledge brokering. British Medical Journal 334: 129-132.

Makkar, Steve R., Anna Williamson, Tari Turner, Sally Redman, and Jordan Louviere. 2015. Using conjoint analysis to develop a system to score research engagement actions by health decision makers. Health Research Policy and Systems 13: 22.

March, James G. 1991. Exploration and Exploitation in Organizational Learning. Organization Science 2: 71-87.

March, James G., and Johan P. Olsen. 2011. The Logic of Appropriateness. In The Oxford Handbook of Political Science, ed. R. E. Goodin. Oxford: Oxford University Press.

Martin, Ben R. 2011. The Research Excellence Framework and the 'impact agenda': are we creating a Frankenstein monster? Research Evaluation 20(3): 247-254.

Matt, Mireille, Ariane Gaunand, Pierre-Benoit Joly, and Laurence Colinet. 2017. Opening the black box of impact - Ideal-type impact pathways in a public agricultural research organization. Research Policy 46: 207-218.

Mazzucato, Mariana. 2018. Mission-oriented innovation policies: challenges and opportunities. Journal of Industrial and Corporate Change 27: 803-815.

McCright, Aaron M., and Riley E. Dunlap. 2010. Anti-reflexivity. The American Conservative Movement's Success in Undermining Climate Science and Policy. Theory Culture \& Society 27: $100-133$.

Merton, Robert K. 1973. The Sociology of Science: Theoretical and Empirical Investigations. Chicago: University of Chicago Press.

Meyer, Ryan. 2011. The Public Values Failures of Climate Science in the US. Minerva 49(1): 47-70. 
Molas-Gallart, Jordi, and Puay Tang. 2011. Tracing "productive interactions" to identify social impacts: an example from the social sciences. Research Evaluation 20: 219-226.

Mthiyane, Helen, and Jonathan Breckon. 2020. Alliance for Useful Evidence: Our Impact, 2016-2019. London: Alliance for Useful Evidence.

Muhonen, Reetta, Paul Benneworth, and Julia Olmos-Peñuela. 2020. From productive interactions to impact pathways: Understanding the key dimensions in developing SSH research societal impact. Research Evaluation 29: 34-47.

Nutley, Sandra, Isabel Walter, and Huw Davies. 2007. Using Evidence: How Research Can Inform Public Services. Bristol: Policy Press.

Olmos-Peñuela, Julia, Elena Castro-Martínez, and Pablo D'Este. 2014. Knowledge transfer activities in social sciences and humanities: Explaining the interactions of research groups with non-academic agents. Research Policy 43: 696-706.

Ouimet, Mathieu, et al. 2010. Correlates of consulting research evidence among policy analysts in government ministries: a cross-sectional survey. Evidence \& Policy 6(4): 433-460.

Parsons, Wayne. 2002. From Muddling Through to Muddling Up - Evidence Based Policy Making and the Modernisation of British Government. Public Policy and Administration 17: 43-60.

Penfield, Teresa, Matthew J. Baker, Rosa Scoble, and Michael C. Wykes. 2013. Assessment, evaluations, and definitions of research impact: A review. Research Evaluation 23: 21-32.

Perl, Anthony. 2020. Studying policy dynamics: policy cycles and regimes. In A Modern Guide to Public Policy, eds. Giliberto Capano and Michael Howlett. Cheltenham, UK/ Northampton, MA, USA: Edward Elgar: 41-57.

Pielke, Roger A. 2007. The honest broker: making sense of science in policy and politics. Cambridge: Cambridge University Press.

Rein, Martin, and Donald Schön. 1993. Reframing policy discourse. The Argumentative Turn in Policy Analysis 6: 145-166.

Reinecke, Sabine. 2015. Knowledge brokerage designs and practices in four European climate services: A role model for biodiversity policies? Environmental Science and Policy 54: 513-521.

Sabatier, Paul A. 1988. An advocacy coalition framework of policy change and the role of policy-oriented learning therein. Policy Sciences 21: 129-168.

Sanderson, Ian. 2002. Evaluation, policy learning and evidence-based policy making. Public Administration 80: $1-22$.

Sanderson, Ian. 2009. Intelligent Policy Making for a Complex World: Pragmatism, Evidence and Learning. Political Studies 57: 699-719.

Sarkki, Simo. 2017. Balancing credibility, relevance and legitimacy: A critical assessment of trade-offs in science-policy interfaces. Science and Public Policy 41: 194-206.

Schmidt, Vivien A. 2002. Does Discourse Matter in the Politics of Welfare State Adjustment? Comparative Political Studies 35: 168-193.

Schmidt, Vivien A. 2008. Discursive institutionalism: The explanatory power of ideas and discourse. Annual Review of Political Science 11: 303-326.

Schmidt, Vivien A. 2010. Taking ideas and discourse seriously: explaining change through discursive institutionalism as the fourth "new institutionalism." European Political Science Review 2: 1-25.

Schmidt, Vivien A. 2012. The State and Political Economic Change: Beyond Rational Choice and Historical Institutionalism to Discursive Institutionalism. In State, Globalization and Multilateralism: The challenges of institutionalizing regionalism, ed. M. Telò. Dordrecht: Springer Netherlands.

Schmidt, Vivien A. 2016. The roots of neo-liberal resilience: Explaining continuity and change in background ideas in Europe's political economy. British Journal of Politics \& International Relations 18: 318-334.

Schmidt, Vivien A. 2017. Britain-out and Trump-in: a discursive institutionalist analysis of the British referendum on the EU and the US presidential election. Review of International Political Economy 24: 248-269.

Scott, Richard. 2014. Institutions and Organizations. USA Stanford University: Sage.

Searle, John R. 1969. Speech acts: An essay in the philosophy of language. Cambridge: Cambridge University Press.

Seeleib-Kaiser, Martin, and Timo Fleckenstein. 2007. Discourse, learning and welfare state change: the case of German labour market reforms. Social Policy Administration 41: 427-448.

Seo, Myeong-Gu, and W.E. Douglas Creed. 2002. Institutional contradictions, praxis, and institutional change: A dialectical perspective. Academy of Management Review 27: 222-247. 
Shackley, Simon, and Brian Wynne. 1996. Representing uncertainty in global climate change science and policy: Boundary-ordering devices and authority. Science, Technology, \& Human Values 21: 275-302.

Smith, Katherine. 2013a. Beyond evidence based policy in public health. The interplay of ideas. Basingstoke: Palgrave Macmillan.

Smith, Katherine. 2013. Understanding the Influence of Evidence in Public Health Policy: What Can We Learn from the 'Tobacco Wars'? Social Policy \& Administration 47: 382-398.

Spaapen, Jack, and Leonie Van Drooge. 2011. Introducing "productive interactions" in social impact assessment. Research Evaluation 20: 211-218.

Stilgoe, Jack, Richard Owen, and Phil Macnaghten. 2013. Developing a framework for responsible innovation. Research Policy 42: 1568-1580.

Stirling, Andrew. 2007. Risk, precaution and science: towards a more constructive policy debate. $E M B O$ Reports 8: 309-315.

Strassheim, Holger. 2018. Policy as a body of expertise. In Policy, Process and Governing, eds. H.K. Colebatch, and R. Hoppe, 89-108. Cheltenham, UK / Northampton, MA, USA: Edward Elgar.

Thomas, Duncan A., Maria Nedeva, Mayra Tirado, and Merle Jacob. 2020. Changing research on research evaluation: A critical literature review to revisit the agenda. Research Evaluation 29(3): 275-288.

Thompson, D.S., et al. 2007. Interventions aimed at increasing research use in nursing: a systematic review. Implement Science 2: 15.

Topp, Lene, David Mair, Laura Smillie, and Paul Cairney. 2018. Knowledge management for policy impact: the case of the European Commission's Joint Research Centre. Palgrave Communications 4: 87.

Turnhout, Esther, Matthijs Hisschemoller, and Herman Eijsackers. 2007. Ecological indicators: Between the two fires of science and policy. Ecological Indicators 7: 215-228.

Upham, Paul, and Leonie Dendler. 2015. Scientists as policy actors: A study of the language of biofuel research. Environmental Science \& Policy 47: 137-147.

Van Der Arend, Jenny. 2014. Bridging the research/policy gap: policy officials' perspectives on the barriers and facilitators to effective links between academic and policy worlds. Policy Studies 35: 611-630.

Van Der Sluijs, Jeroen, Josee Van Eijndhoven, Simon Shackley, and Brian Wynne. 1998. Anchoring devices in science for policy: The case of consensus around climate sensitivity. Social Studies of Science 28 : 291-323.

Wallace, Matthew L., and Ismael Rafols. 2015. Research Portfolio Analysis in Science Policy: Moving from Financial Returns to Societal Benefits. Minerva 53(2): 89-115.

Watermeyer, Richard. 2016. Impact in the REF: issues and obstacles. Studies in Higher Education 41(2): 199-214.

Weber, K. Matthias, and Harald Rohracher. 2012. Legitimizing research, technology and innovation policies for transformative change: Combining insights from innovation systems and multi-level perspective in a comprehensive 'failures' framework. Research Policy 41: 1037-1047.

Weible, C.M., et al. 2010. Harnessing expert-based information for learning and the sustainable management of complex socio-ecological systems. Environmental Science \& Policy 13(6): 522-534.

Weichselgartner, Jergen, and Roger Kasperson. 2010. Barriers in the science-policy-practice interface: Toward a knowledge-action-system in global environmental change research. Global Environmental Change 20: 266-277.

Weiss, Carol. 1979. The Many Meanings of Research Utilization. Public Administration Review 39: 426-431.

Weiss, Carol. 1982. Policy research in the context of diffuse decision making. The Journal of Higher Education 53: 619-639.

Weiss, Carol, Erin Murphy-Graham, Anthony Petrosino, and Alison G. Gandhi. 2008. The Fairy Godmother-and Her Warts. American Journal of Evaluation 29: 29-47.

Wilkinson, Clare. 2017. Evidencing impact: a case study of UK academic perspectives on evidencing research impact. Studies in Higher Education 44(1): 1-14.

Publisher's Note Springer Nature remains neutral with regard to jurisdictional claims in published maps and institutional affiliations. 